\title{
THE ANAESTHETIC PROBLEMS ASSOCIATED WITH GIANT TENSION CYSTS OF THE LUNG
}

\author{
BY \\ T. CECIL GRAY AND F. RONALD EDWARDS \\ From the Departments of Anaesthesia and Thoracic Surgery, Liverpool University
}

Giant congenital cysts of the lung often have a one-way valvular mechanism in the feeding bronchus, and at operation certain anaesthetic difficulties may be encountered which demonstrate the inefficiency of modern methods of artificial ventilation of the lungs in such a condition. The following case is an excellent example.

\section{CASE History}

A boy aged 5 years was admitted to the Liverpool Chest Surgical Centre complaining of recurrent attacks of a dry throat cough. He had no dyspnoea and there was neither sputum production nor haemoptysis. His general condition was good.

Routine radiography showed a picture suggestive of a congenital cystic condition of his left lung, which had a hyperlucent appearance with a few trabeculae. The trachea and mediastinum were displaced to the right side and there was an associated mediastinal hernia (Plate XXII).

Bronchograms showed some filling of indeterminate upper lobe divisions, but there was no apparent filling of the lower lobe. The right lung was normal.

On bronchoscopy the larynx, trachea, and carina were normal. The left upper lobe and lower lobe bronchus were present, but the spur between the two was rotated through $90^{\circ}$.

It was thought that the whole left lung was cystic and it was decided to perform a pneumonectomy. The vital capacity of the patient before operation was $500 \mathrm{c.cm}$.

ANAesthesia AND Operation.-Premedication with atropine, $0.65 \mathrm{mg}$., was given, and because of the boy's fear of "the needle," anaesthesia was induced with nitrous oxide followed by cyclopropane.

As soon as consciousness was lost $2 \mathrm{mg}$. of "tubarine" was given intravenously as a test dose, and was followed after an interval of two minutes by a further $4 \mathrm{mg}$. and $1.5 \mathrm{ml}$. of a 5 per cent solution of thiopentone. Apnoea resulted, and a No. 6 Magill's endotracheal tube was inserted under vision and connected to a Water's to-and-fro absorption circuit. At once it was noticed that full oxygenation could not be maintained even by brisk inflation of the lungs with pure oxygen. After inflation the gases were not returned to the rebreathing bag, rather as if the endotracheal tube were in the oesophagus. It was realized that this was due to a progressive inflation of the cystic lung, the valvular mechanism preventing the reflux of gases.

In view of this difficulty the respiratory function was restored by the intravenous injection of pros- tigmin, $1 \mathrm{mg}$., buffered with atropine, $0.65 \mathrm{mg}$. This brought about a considerable improvement, and the anaesthesia was maintained with cyclopropane.

When the chest was opened it seemed that the whole of the left side was occupied by a grossly distended cyst or series of cysts having the appearance of an over-inflated toy balloon. The cystic area was about 8 in. in diameter, the size of a small football.

One of the cysts was aspirated, and this allowed the whole area to collapse, which indicated that there was complete intracystic communication and suggested a multilocular single cyst. The bronchus supplying the cyst was then clamped, and from this moment the respiratory condition became completely satisfactory. The lungs could now be inflated with ease, and the patient's colour, which hitherto had shown persistent slight cyanosis, became normal.

After dissection it was found that the cyst was replacing the upper part of the upper lobe. The lingula was present, but both it and the whole lower lobe was infantile in size and atelectatic (see Figure). After removal of the cyst and the remains of the upper lobe, the lower lobe was found to expand when inflated by the anaesthetist and it was decided to leave it in situ. The impression was that this was the first time that this lobe had expanded in the life of the patient.

At the end of the operation the trachea was aspirated of a small amount of muco-purulent material, and the patient's cough reflex was actively present when the endotracheal tube was removed.

Convalescence.-The very small infantile left lower lobe gradually expanded, and by the sixth day was aerating satisfactorily. Nineteen days postoperatively radiographs showed that there was very good expansion of the lower lobe and just a little fluid in the upper part of the pleural cavity.

The subsequent convalescence was completely satisfactory and uneventful. The child's vital capacity before discharge from hospital was $800 \mathrm{c.cm}$. A radiograph taken three months after operation shows a relatively normal chest (Plate XXIII $b$ ).

We are grateful to Dr. Whitwell for the following pathological report:

" The specimen consisted of a globular baggy mass with a shiny white capsule, and there was an attached small bit of brown tissue. This was covered by pleura, except at one point where the specimen had been detached from the body. This point of attachment contained minute thin-walled bronchi (Plate XXIII a). 


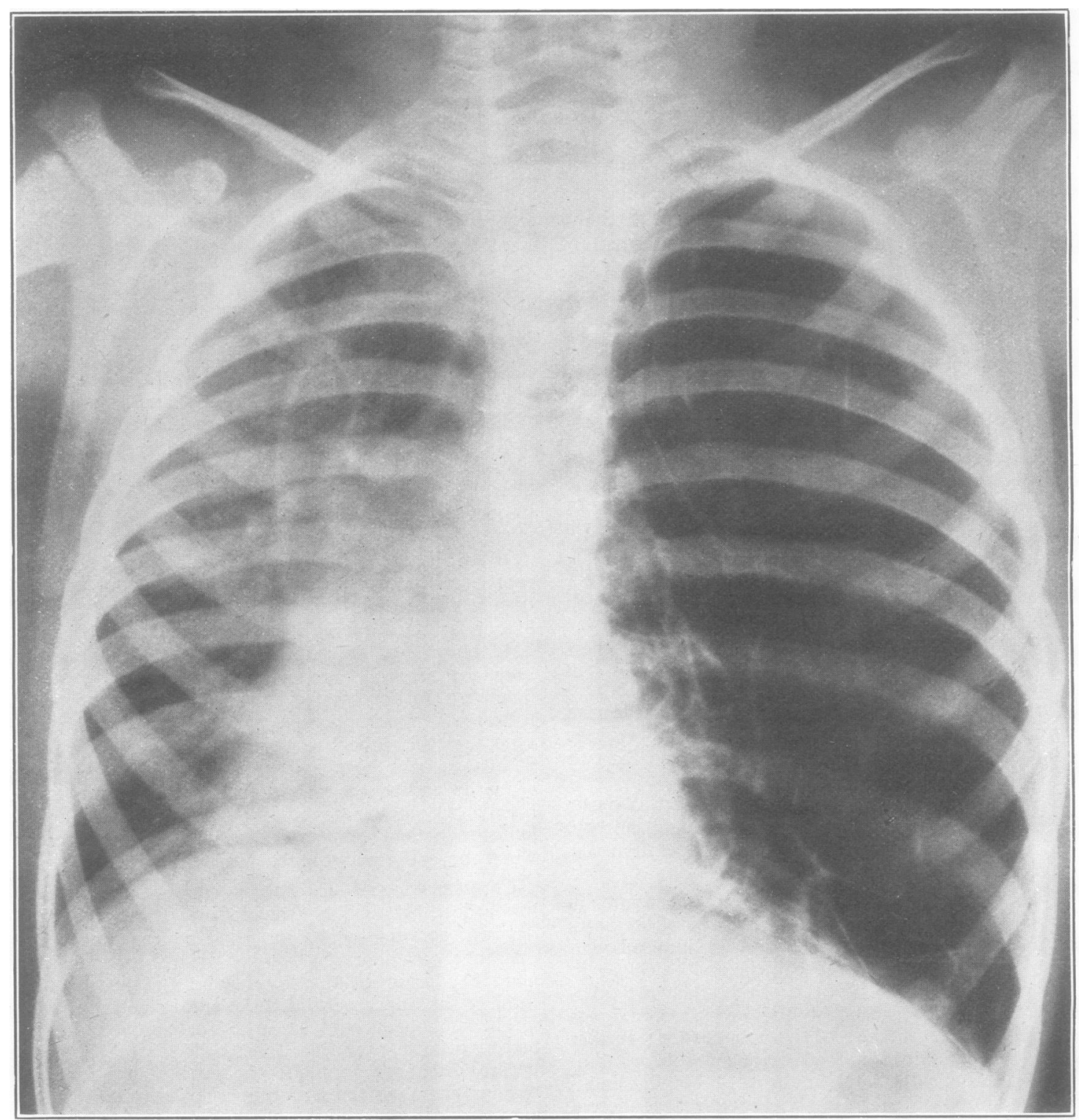

Plate XXII.-Pre-operative radiograph showing a picture suggestive of a congenital cystic condition of the left lung, which has a hyperlucent appearance with a few trabeculae. The trachea and mediastinum are displaced to the right and there is an associated mediastinal hernia. 


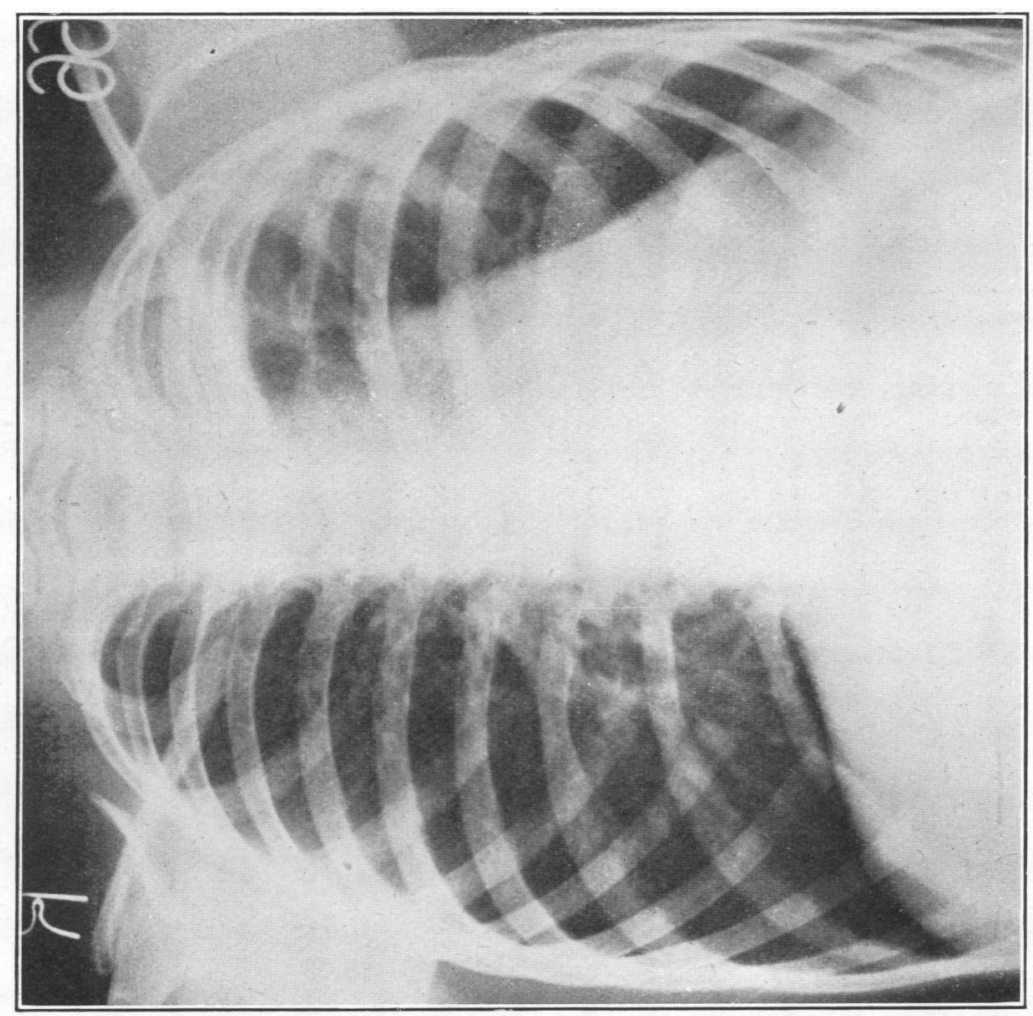

2)

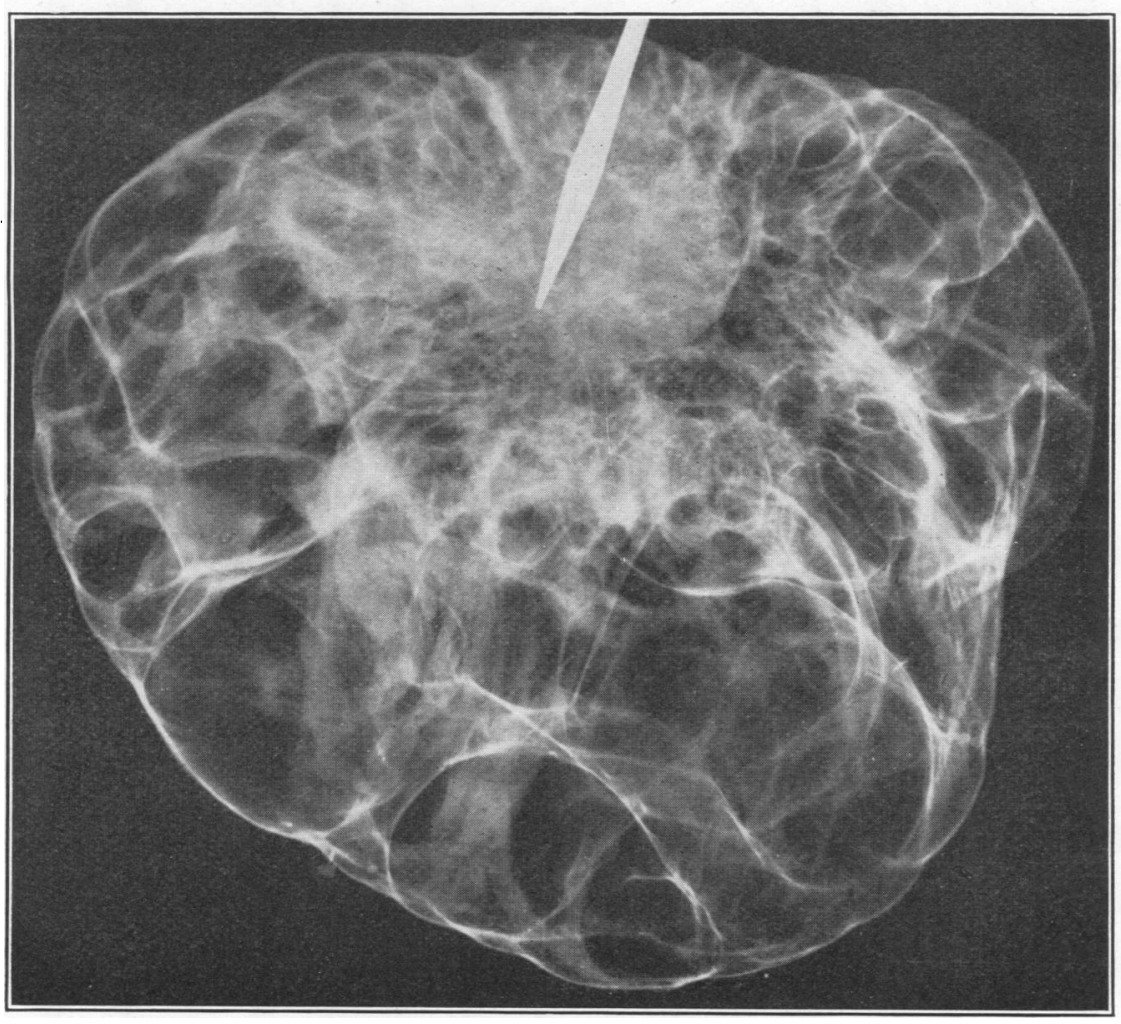


"Section of the mass showed that it had a multilocular structure, the cysts being largest at the periphery and smallest near the hilum. The appearance was more like a polycystic kidney or an ovarian cyst than lung.

"Histologically the mass was composed of fibrous trabeculae which divided it into cysts. These had an epithelial lining, usually flattened, but cuboidal in places. The cyst wall contained muscle and cartilage in places, but not in any orderly manner.
When the respiratory function in this case was restored practically to normal by prostigmin, the condition of the child improved greatly. It was, however, not entirely satisfactory until the bronchus connecting with the cyst had been clamped. Had a suitable bronchial occluder been available it would have been of great value. Once it was in position the lungs could have been inflated without fear of distending the cyst. It would have been withdrawn after clamping of the

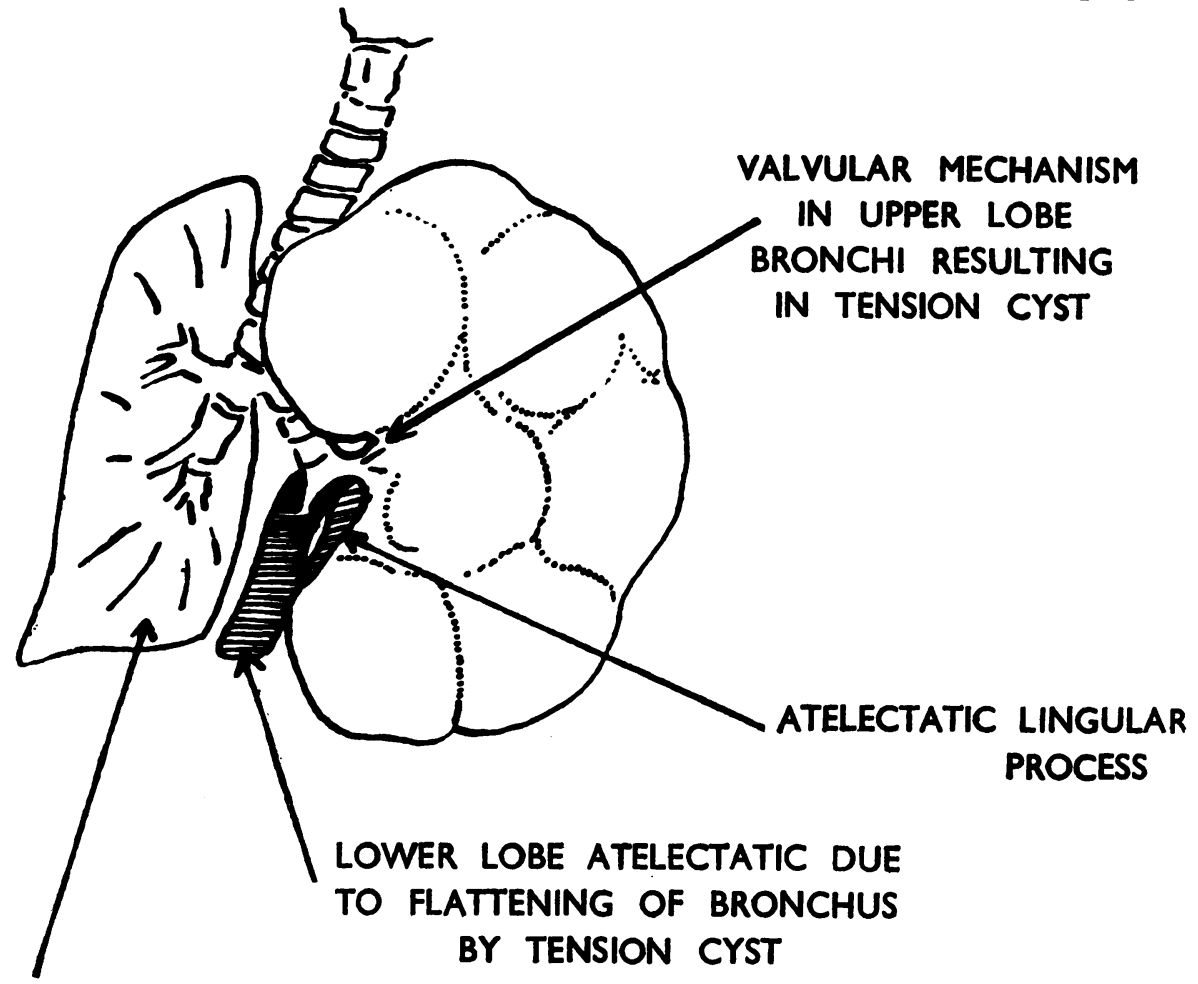

\section{COMPRESSED}

\section{RIGHT LUNG}

" The attached dark brown tissue consisted of lung which contains few bronchioles but some cysts lined by columnar epithelium."

\section{Discussion}

This case illustrated well the dangers of abolishing or impairing the natural respiratory function in certain pulmonary conditions. Where valvular mechanisms are present, as in congenital or emphysematous cysts and recent broncho-pleural fistulae, attempted inflation of the lungs simply results in distension of the cyst or pleural cavity and, whilst the cyst or broncho-pleural communication is still untreated, aeration is bound to be defective. bronchus supplying the cyst in order to inflate the remaining lower lobe. It is important, however, to avoid manual inflation of the lungs before the insertion of the occluder, as this would lead to over-distension of the cyst.

In the absence of efficient bronchial occlusion the natural respiratory efforts must be maintained until the bronchus is clamped.

\section{SUMMARY}

A tension cyst of the lung is described, and the inadvisability of impairing the normal respiratory function during the anaesthesia for such conditions is stressed. 